\title{
Mast cell derived carboxypeptidase A3 is decreased among patients with advanced coronary artery disease
}

\author{
Łukasz Lewicki ${ }^{1,2,3}$, Janusz Siebert ${ }^{1,4}$, Tomasz Koliński ${ }^{5}$, Karolina Piekarska ${ }^{5}$, \\ Magdalena Reiwer-Gostomska ${ }^{4}$, Radosław Targoński ${ }^{3}$, \\ Piotr Trzonkowski ${ }^{6}$, Natalia Marek-Trzonkowska ${ }^{5}$ \\ ${ }^{1}$ University Center for Cardiology, Gdansk, Poland \\ ${ }^{2}$ Department of Machine Design and Automotive Engineering, Faculty of Mechanical Engineering, \\ Gdansk University of Technology, Gdansk, Poland \\ ${ }^{3}$ Pomeranian Cardiology Centers, Wejherowo, Poland \\ ${ }^{4}$ Department of Family Medicine, Medical University of Gdansk, Poland \\ ${ }^{6}$ Department of Family Medicine, Laboratory of Immunoregulation and Cellular Therapies, \\ Medical University of Gdansk, Poland \\ ${ }^{7}$ Department of Clinical Immunology and Transplantology, Medical University of Gdansk, Poland
}

\begin{abstract}
Background: Coronary artery disease (CAD) affects milions of people and can result in myocardial infarction (MI). Previously, mast cells (MC) have been extensively investigated in the context of hypersensitivity, however as regulators of the local inflammatory response they can potentially contribute to $C A D$ and/or its progression. The aim of the study was to assess if serum concentration of MC proteases: carboxypeptidase A3, cathepsin $G$ and chymase 1 is associated with the extension of CAD and MI.

Methods: The 44 patients with angiographically confirmed CAD (23 subjects with non-ST-segment elevation MI [NSTEMI] and 21 with stable CAD) were analyzed. Clinical data were obtained as well serum concentrations of carboxypeptidase A3, cathepsin $G$ and chymase 1 were also measured.

Results: Patients with single vessel CAD had higher serum concentration of carboxypeptidase than those with more advanced CAD (3838.6 $\pm 1083.1 \mathrm{pg} / \mathrm{mL}$ vs. $2715.6 \pm 442.5 \mathrm{pg} / \mathrm{mL} ; p=0.02)$. There were no significant differences in levels of any protease between patients with stable CAD and those with NSTEMI. Patients with hypertension had $\approx 2$-fold lower serum levels of cathepsin $G$ than normotensive individuals ( $4.6 \pm 0.9 \mathrm{pg} / \mathrm{mL}$ vs. $9.4 \pm 5.8 \mathrm{pg} / \mathrm{mL} ; \mathrm{p}=0.001)$. Cathepsin $\mathrm{G}$ levels were also decreased in sera of the current smokers as compared with non-smokers $(3.1 \pm 1.2 \mathrm{ng} / \mathrm{mL}$ vs. $5.8 \pm 1.2 \mathrm{ng} / \mathrm{mL}$, $p=0.02)$.

Conclusions: Decreased serum level of carboxypeptidase is a hallmark of more advanced CAD. Lower serum levels of carboxypeptidase $A 3$ and catepsin $G$ are associated with risk factors of blood vessel damage suggesting a protective role of these enzymes in CAD. (Cardiol J 2019; 26, 6: 680-686)

Key words: mast cells, carboxypeptidase A3, cathepsin G, chymase 1, coronary artery disease
\end{abstract}

Address for correspondence: Łukasz Lewicki, MD, PhD, University Center for Cardiology, ul. Dębinki 2, 80-211 Gdańsk, Poland, e-mail: luklewicki@gmail.com

Received: 27.05.2017 Accepted: 16.01.2018 


\section{Introduction}

Chronic inflammation plays an important role in the pathogenesis of coronary artery disease (CAD) and acute myocardial infarction (AMI).The link between mast cell (MC) proteases and a local inflammation process is an attractive research area. After activation, $\mathrm{MC}$ releases a wide range of proteases that have a potential pro or antiinflammatory effect [1-3]. The major MC proteases include tryptase, chymase 1, carboxypeptidase A3 and cathepsin G.

In previously published work, it was shown that tryptase and endothelin-1 released from activated $\mathrm{MC}$ are elevated in patients with an AMI [4]. Therefore, in the current study theaim was to analyze if other $\mathrm{MC}$ proteases chymase 1, carboxypeptidase $A 3$ and cathepsin $G$ play also have a role in CAD and AMI.

Chymase 1 is a serine protease stored in MC. It is released after stimulation during an inflammatory or ischemic injury that is known to be a hallmark of AMI. The protein release is associated with activation of matrix metalloproteinase- 9 , which was shown to increase infarct size in an experimental model [5]. Oyamada et al. [6] have shown, that chymase 1 inhibition results in myocardial protection and attenuates fibrosis after AMI. In addition, chymase plays a crucial role in transformation of angiotensin I to angiotensin II independent from angiotensin converting enzyme [7].

Cathepsin $\mathrm{G}$ is a serine protease also synthesized and stored in MC. However, MC are not the only source of the enzyme, it is also released from activated neutrophils and macrophages [8-10]. Despite that cathepsin G may promote early atherogenesis as it is an elastase [11] and collagenase activator [12], Wang et al. [13] suggested that cathepsin $G$ promotes early atherogenesis through its elastinolytic activity, but at the same time suppresses late progression of atherosclerosis. In their study, patients with atherosclerosis had significantly reduced plasma levels of cathep$\sin G$ that were in negative correlation with total cholesterol and low density lipoprotein (LDL), but not high density lipoprotein (HDL) or triglycerides, suggesting a role of cathepsin $\mathrm{G}$ in degradation of LDL without affecting HDL or triglycerides [13].

A carboxypeptidase A3 (CPA3) is a zinc metalloprotease that is released from $\mathrm{MCs}$ and basophils as well. This enzyme degrades proteins and peptides, including the apolipoprotein $\mathrm{B}$; a component of LDL particles [14]. Upon MC activation and degranulation, CPA3 with the chymases and tryptases interacts with heparin proteoglycans [15]. It was shown to play a role in the inactivation of endothelin $[16,17]$ and degradation of angiotensin II [18], which suggests its antihypertensive activity.

The aim of the study was to check if a concentration of $\mathrm{MC}$ derived proteases is elevated in sera of patients with different extensions of $\mathrm{CAD}$, and thus to assess the role of $\mathrm{MC}$ in its pathogenesis.

\section{Methods}

This was a prospective and single-center study. The study was conducted according to the Declaration of Helsinki and the protocol was reviewed and approved by the local ethics committee. All patients gave written informed consent.

\section{Patients}

Between November 2012 and May 2013, 44 consecutive patients were prospectively screened who underwent diagnostic coronary angiography because of non-ST-segment elevation myocardial infarction (NSTEMI) or stable angina with a positive stress test. All the procedures were performed at the Department of Invasive Cardiology, Pomeranian Cardiology Centers, Wejherowo, Poland. Patients with renal failure, malignancy, and acute or chronic inflammatory disease were excluded from the study. Finally, 44 patients (23 NSTEMI and 21 with stable angina) were included. Complete demographic and clinical data were obtained. Accordingly to the extension of $\mathrm{CAD}$, patients were divided into two groups: subjects with one vessel CAD and those with two or three vessel CAD.

\section{Blood sampling and laboratory tests}

The blood samples were obtained after puncture of a radial or a femoral artery and they were drawn from the vascular sheath during a coronary angiography.

Then, blood samples were centrifuged at $1000 \times \mathrm{g}$ for $15 \mathrm{~min}$ to obtain serum. Subsequently, standard clinical parameters were measured and the remaining serum was apportioned into $0.5 \mathrm{~mL}$ aliquots, and stored at $-80^{\circ} \mathrm{C}$ until analysis of $\mathrm{CPA} 3$, cathepsin $\mathrm{G}$ and chymase 1 .

\section{Measurement of CPA3, cathepsin G and chymase 1 \\ Carboxypeptidase A3, cathepsin G and chy- mase 1 concentrations were measured with ELISA (Cloud-Clone Corp., Houston, TX, USA) according to manufacturer instructions. The lower limit of}


Table 1. Demographic and biochemical data of 44 patients with significant coronary artery disease (CAD) according to the extension of CAD.

\begin{tabular}{lccc}
\hline & 1 vessel CAD $(\mathbf{n}=\mathbf{1 1})$ & 2-3 vessel CAD (n = 33) & P \\
\hline Age [years] & $68.3 \pm 7.1$ & $67.5 \pm 2.6$ & 0.7 \\
Male/female & $5 / 6$ & $19 / 14$ & 0.5 \\
Body mass index $\left[\mathrm{kg} / \mathrm{m}^{2}\right]$ & $29.9 \pm 1.5$ & 0.6 \\
Total cholesterol $[\mathrm{mg} / \mathrm{dL}]$ & $20.7 \pm 3.7$ & $171.3 \pm 17$ & 0.01 \\
LDL cholesterol $[\mathrm{mg} / \mathrm{dL}]$ & $220.1 \pm 48.1$ & $98.4 \pm 16$ & 0.002 \\
HDL cholesterol $[\mathrm{mg} / \mathrm{dL}]$ & $158.6 \pm 46.8$ & $44.6 \pm 4.2$ & 0.8 \\
Serum creatinine $[\mathrm{mg} / \mathrm{dL}]$ & $45.7 \pm 9.3$ & $1.2 \pm 0.1$ & 0.1 \\
eGFR & $1.7 \pm 1.3$ & $53.5 \pm 4.4$ & 0.1 \\
LVEF [\%] & $45.9 \pm 11.4$ & $47.6 \pm 4.3$ & 0.9 \\
Arterial hypertension & $48.2 \pm 5.5$ & 13 & 0.2 \\
Diabetes & 11 & 15 & 0.6 \\
History of previous MI & 4 & 24 & 0.005 \\
History of stroke/TIA & 2 & 7 & 0.7 \\
Current smoker & 3 & 18 & 0.7 \\
\hline
\end{tabular}

eGFR — estimated glomerular filtration rate; HDL — high density lipoprotein; LDL — low density lipoprotein; LVEF — left ventricular ejection fraction; $\mathrm{MI}$ - myocardial infarction; TIA — transient ischemic attack

Table 2. Demographic, biochemical and clinical data of 23 patients with non-ST-elevation myocardial infarction (NSTEMI) and 21 patients with stable coronary artery disease (CAD).

\begin{tabular}{lccc}
\hline & NSTEMI $(\mathbf{n}=\mathbf{2 3})$ & Stable CAD $(\mathbf{n}=\mathbf{2 1})$ & $\mathbf{P}$ \\
\hline Age [years] & $68.5 \pm 3.8$ & $66.8 \pm 3.3$ & 0.5 \\
Body mass index $\left[\mathrm{kg} / \mathrm{m}^{2}\right]$ & $30 \pm 1.7$ & $30.3 \pm 2.3$ & 0.8 \\
Total cholesterol $[\mathrm{mg} / \mathrm{dL}]$ & $198.1 \pm 28$ & $167.5 \pm 20.9$ & 0.08 \\
LDL cholesterol $[\mathrm{mg} / \mathrm{dL}]$ & $124.9 \pm 27.3$ & $100.9 \pm 22.5$ & 0.2 \\
HDL cholesterol $[\mathrm{mg} / \mathrm{dL}]$ & $44.3 \pm 5.3$ & $45.6 \pm 5.6$ & 0.7 \\
Serum creatinine $[\mathrm{mg} / \mathrm{dL}]$ & $1.5 \pm 0.6$ & $1.1 \pm 0.1$ & 0.2 \\
eGFR & $47.3 \pm 6.6$ & $56.4 \pm 4.8$ & 0.03 \\
CRP & $33.2 \pm 25.6$ & $5.3 \pm 2.8$ & 0.03 \\
Arterial hypertension & 21 & 18 & 0.5 \\
Diabetes & 9 & 10 & 0.6 \\
History of previous MI & 7 & 17 & 0.001 \\
History of stroke/TIA & 3 & 0 & 0.09 \\
Current smoker & 6 & 4 & 0.6 \\
3 vessel CAD/1-2 vessel CAD & $3 / 20$ & $9 / 12$ & 0.03 \\
LVEF [\%] & $45.9 \pm 4.2$ & $49.7 \pm 5.8$ & 0.3 \\
\hline
\end{tabular}

eGFR — estimated glomerular filtration rate; CRP — C-reactive protein; HDL — high density lipoprotein; LDL — low density lipoprotein; LVEF - left ventricular ejection fraction; MI - myocardial infarction; TIA - transient ischemic attack

detection of CPA3, cathepsin $\mathrm{G}$ and chymase 1 was $<3.0 \mathrm{pg} / \mathrm{mL},<0.065 \mathrm{ng} / \mathrm{mL}$ and $<13.5 \mathrm{pg} / \mathrm{mL}$, respectively. Protein concentration was measured spectrophotometrically (Perkin Elmer VICTOR X4) at a wavelength of $450 \pm 10 \mathrm{~nm}$ and was determined by comparing the O.D. of samples to a standard curve.

\section{Statistical analysis}

The results are expressed as mean \pm standard deviation. Comparisons between groups were performed using the t-Student test for continuous variables and $\chi^{2}$ test for categorical variables. Wizard Statistics 1.8.16 software was used for analysis, p-value $<0.05$ was considered statistically significant. 


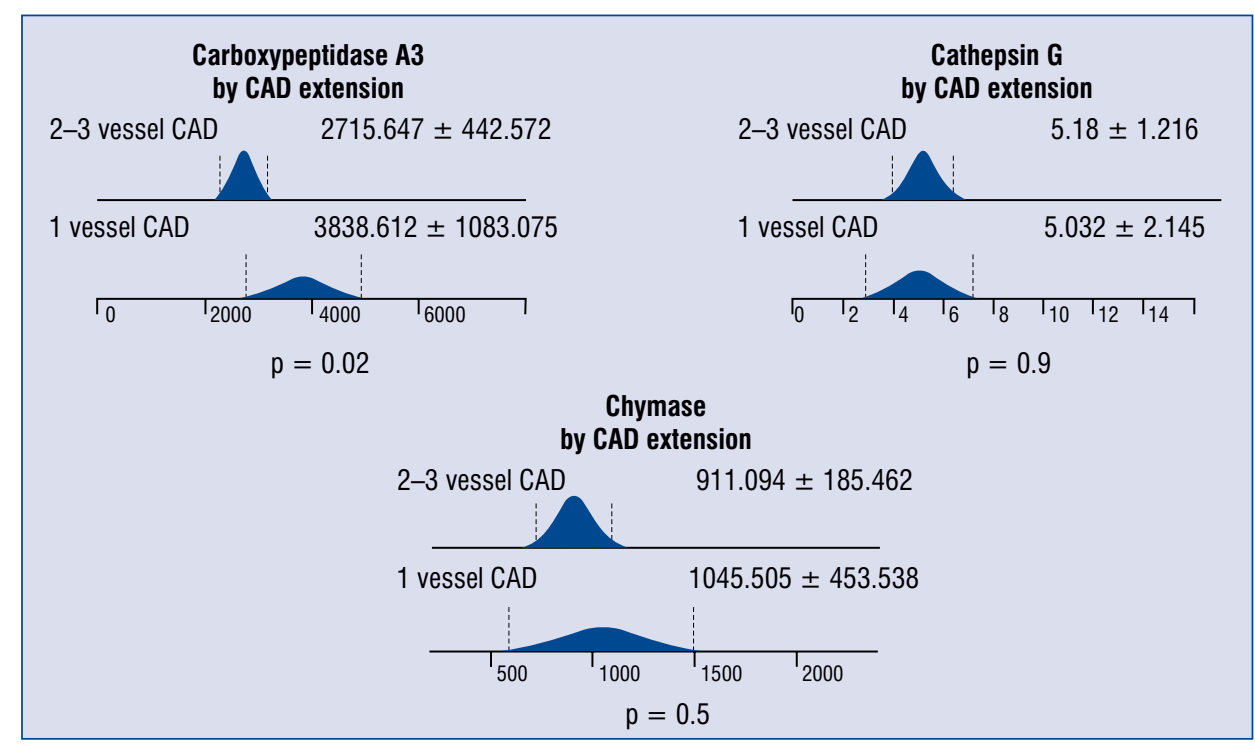

Figure 1. The differences in serum concentrations of carboxypeptidase $A 3(\mathrm{pg} / \mathrm{mL})$, chymase $1(\mathrm{pg} / \mathrm{mL})$ and cathepsin $\mathrm{G}$ $(\mathrm{ng} / \mathrm{mL})$ in patients with single vessel coronary artery disease (CAD) and 2 or3 vessel CAD.

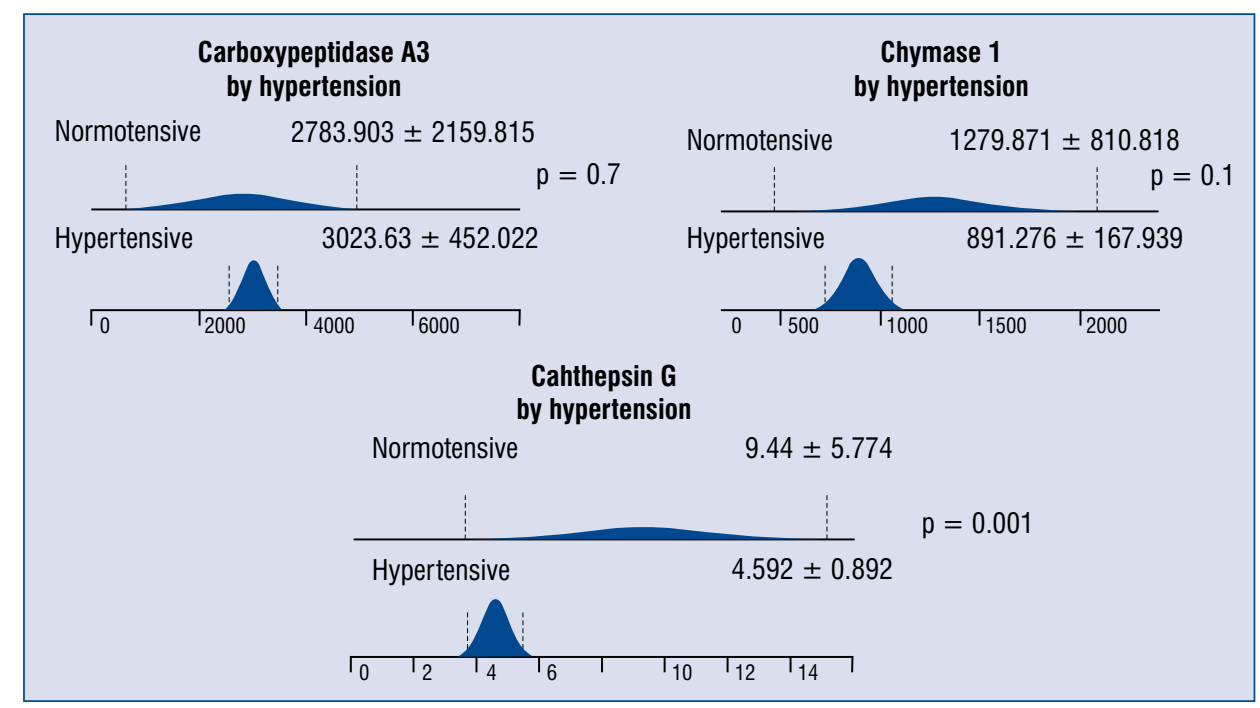

Figure 2. The differences in serum concentrations of carboxypeptidase $A 3(\mathrm{pg} / \mathrm{mL})$, chymase $1(\mathrm{pg} / \mathrm{mL})$ and cathepsin $\mathrm{G}$ (ng/ml) among patients with or without hypertension.

\section{Results}

The demographic and biochemical data of $44 \mathrm{pa}-$ tients with significant $\mathrm{CAD}$ are presented in Table 1. Patients with more advanced CAD had more often had a history of previous myocardial infarction (MI).

The major clinical and biochemical data of 23 NSTEMI patients were compared to subjects with stable CAD are listed in Table 2. Patients with stable CAD had more often had a history of MI in the past and presented more often with three vessel CAD compared to NSTEMI patients. On the other hand, subjects with NSTEMI had significantly higher levels of $\mathrm{C}$-reactive protein and lower glomerular filtration rate.

Patients with one vessel CAD presented a significantly higher level of carboxypeptidase than those with more advanced CAD. Neither the cathepsin $\mathrm{G}$ nor chymase differed between the two groups (Fig. 1).

Significantly lower levels of cathepsin $\mathrm{G}$ were observed among patients with $\mathrm{CAD}$ and hyperten- 


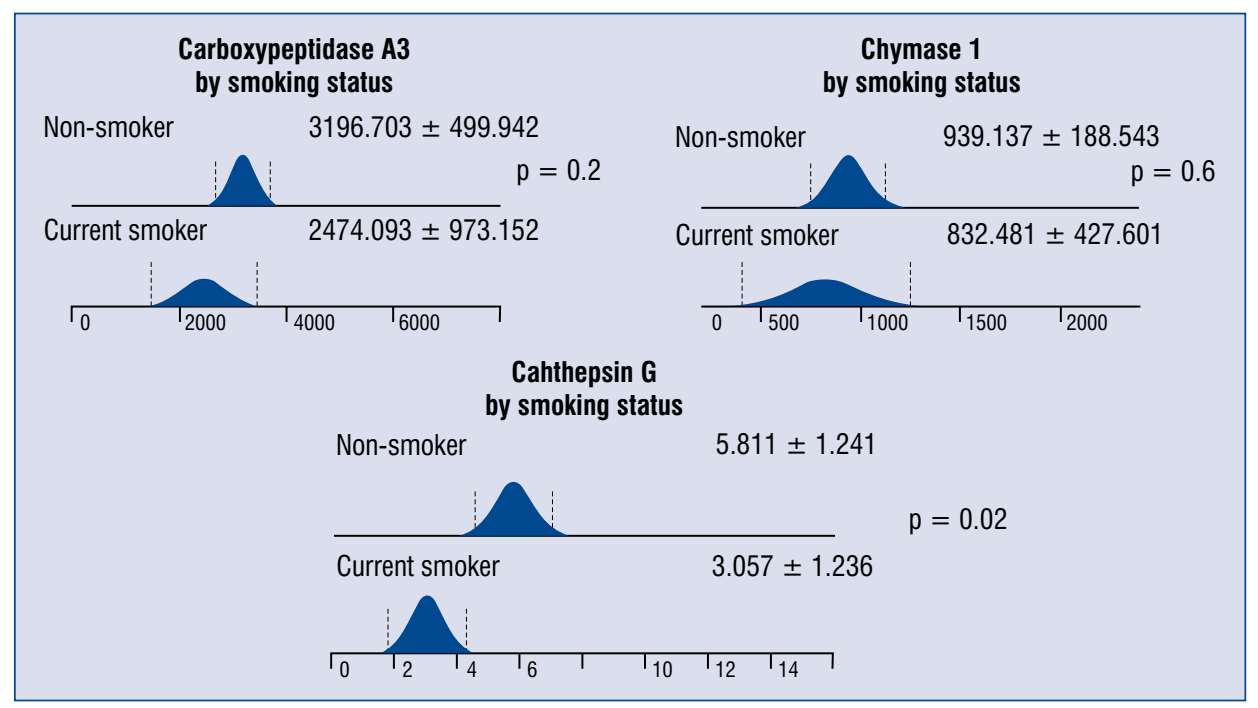

Figure 3. The differences in serum concentrations of carboxypeptidase $A 3(\mathrm{pg} / \mathrm{mL})$, chymase 1 (pg/mL) and cathepsin G $(\mathrm{ng} / \mathrm{ml})$ among patients with coronary artery disease (CAD) according to their smoking status.

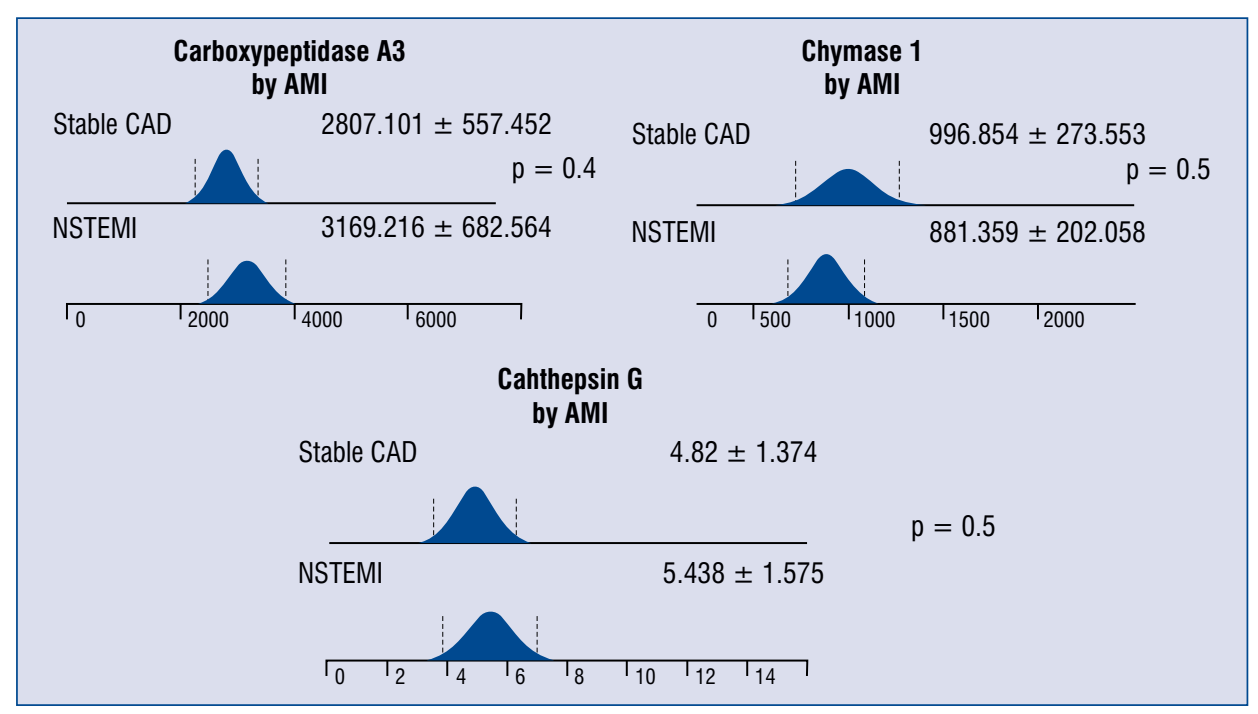

Figure 4. The differences in serum concentrations of carboxypeptidase $A 3(\mathrm{pg} / \mathrm{mL})$, chymase 1 (pg/mL) and cathepsin $\mathrm{G}$ $(\mathrm{ng} / \mathrm{ml})$ in patients with stable coronary artery disease (CAD) and non-ST-segment elevation myocardial infarction (NSTEMI); AMI - acute myocardial infarction.

sion as compared with normotensive CAD subjects (Fig. 2). Lower serum concentrations of cathepsin $\mathrm{G}$ in individuals with CAD were also associated with smoking (Fig. 3).

There were no statistically significant differences in levels of any protease between patients with stable CAD and those with NSTEMI (Fig. 4).

\section{Discussion}

Mast cells have been extensively investigated in the context of hypersensitivity [19] and little is known about their influence on the human body apart from allergic inflammation. However, in the present study it was shown that serum concentration of MC derived enzyme CPA3 was decreased in patients with more advanced CAD. In addition, higher levels of cathepsin $\mathrm{G}$ were found in normotensive CAD patients and in those who were non-smokers. This data has shed new light on MC and the role of their activation in cardiovascular diseases.

Previously, Xiang et al. [20] reported increased chymase concentration in patients with MI. How- 
ever, there is no data concerning a possible association of carboxypeptidase and presence of CAD. In the current study, significantly higher levels of CPA3 were observed in patients with angiographically confirmed single vessel CAD as compared with subjects with advanced two or three vessel disease.

Carboxypeptidase A3 and chymase 1 play a key role in the formation as well as degradation of angiotensin II [18]. Whereas chymase is the main tissue converter of angiotensin I to angiotensin II, CPA3 creates peptides Ang-(1-9) and Ang-(1-7) that antagonize angiotensin II [18]. The peptide angiotensin II is not only a strong vasoconstrictor, but it also can promote atherosclerosis via several biologic activities such as: an increased expression of adhesion molecules on endothelial cells, activation of macrophages and upregulation of matrix metalloproteinases and proinflammatory cytokines $[21,22]$. Therefore, as an indirect antagonist of angiotensin II, CPA3 exerts a protective effect in CAD. CPA3 was also found to degrade another vasoconstrictor - endothelin-1 and was found to play a cardioprotective effect during ischemia-reperfusion injury [23]. In addition, the present study revealed that lower serum concentration of the peptide was characteristic for patients with more advanced $\mathrm{CAD}$ and also for those who were active smokers. As smoking is one of the most widely known risk factors of cardiovascular diseases [24], this data suggests that one of the mechanisms of the deleterious impact of smoking on blood vessels might be an inhibitor of CPA3 production. Thus, all these data together confirms a protective effect of this enzyme in CAD.

When NSTEMI patients were compared with those having stable CAD, nosignificant differences were found in the levels of any of the proteases studied. Previously Xiang et al. [20] reported that serum chymase levels were higher in patients with AMI compared to subjects with stable CAD, however this difference was not statistically significant [20]. The lack of significant differences in serum levels of chymase between patients with $\mathrm{MI}$ and stable CAD in the cited study and chymase and carboxypeptidase of the present research may reflect the fact that an underlying mechanism of angiotensin II regulation influences chronic atherosclerosis rather than a formation of unstable coronary plaque and consequently AMI.

The concentration of cathepsin $\mathrm{G}$ was significantly lower in current smokers and hypertensive patients than in non-smokers and normotensive individuals, respectively. Wang et al. [13] has shown, that cathepsin $\mathrm{G}$ promoted early atherogenesis through its elastinolytic activity, but on the other hand it suppressed late progression of atherosclerosis by degrading LDL. In their study patients with $\mathrm{CAD}$ were characterized with significantly lower levels of cathepsin $\mathrm{G}$ and higher levels of $\mathrm{LDL}$, than individuals without CAD [13]. In the present study, decreased serum concentration of cathepsin $G$ in CAD patients was associated with tabacco smoking or hypertension. Cathepsin $\mathrm{G}$ was found to exert an anti-inflammatory effect by reducing biological activity of inflammatory cytokines [25]. As both hypertension and smoking are associated with inflammation and increased production of pro-inflammatory cytokines [26], lower levels of protease in these patients may reflect an exhaustion of its production in chronic inflammation.

\section{Conclusions}

1. Decreased serum concentration of CPA3 is a hallmark of more advanced CAD.

2. Lower serum levels of CPA3 and catepsin $\mathrm{G}$ are associated with risk factors of blood vessel damage suggesting a protective role of these enzymes in CAD.

\section{Acknowledgements}

This study was supported with funds from the Polish National Science Center on the basis of Decision no. DEC-2012/07/B/NZ5/00017. The founders had no role in study design, data collection and analysis, decision to publish, or preparation of the manuscript.

\section{Conflict of interest: None declared}

\section{References}

1. Kaartinen M, Penttilä A, Kovanen PT. Accumulation of activated mast cells in the shoulder region of human coronary atheroma, the predilection site of atheromatous rupture. Circulation. 1994; 90(4): 1669-1678, indexed in Pubmed: 7923651.

2. Kaartinen M, Penttilä A, Kovanen PT. Mast cells in rupture-prone areas of human coronary atheromas produce and store TNF-alpha. Circulation. 1996; 94(11): 2787-2792, doi: 10.1161/01. cir.94.11.2787, indexed in Pubmed: 8941103.

3. Zhao W, Oskeritzian CA, Pozez AL, et al. Cytokine production by skin-derived mast cells: endogenous proteases are responsible for degradation of cytokines. J Immunol. 2005; 175(4): 2635-2642, doi: 10.4049/jimmunol.175.4.2635, indexed in Pubmed: 16081839 .

4. Lewicki L, Siebert J, Marek-Trzonkowska N, et al. Elevated Serum Tryptase and Endothelin in Patients with ST Segment Elevation Myocardial Infarction: Preliminary Report. Mediators Inflamm. 2015; 2015: 395173, doi: 10.1155/2015/395173, indexed in Pubmed: 26089601. 
5. Oyamada S, Bianchi C, Takai S, et al. Impact of acute myocardial ischemia reperfusion on the tissue and blood-borne reninangiotensin system. Basic Res Cardiol. 2010; 105(4): 513-522, doi: 10.1007/s00395-010-0093-4, indexed in Pubmed: 20340028.

6. Oyamada S, Bianchi C, Takai S, et al. Chymase inhibition reduces infarction and matrix metalloproteinase- 9 activation and attenuates inflammation and fibrosis after acute myocardial ischemia/reperfusion. J Pharmacol Exp Ther. 2011; 339(1): 143-151, doi: 10.1124/jpet.111.179697, indexed in Pubmed: 21795433.

7. Wei CC, Tian B, Perry G, et al. Differential ANG II generation in plasma and tissue of mice with decreased expression of the ACE gene. Am J Physiol Heart Circ Physiol. 2002; 282(6): H2254-H2258, doi: 10.1152/ajpheart.00191.2001, indexed in Pubmed: 12003835.

8. Helske S, Syväranta S, Kupari M, et al. Possible role for mast cell-derived cathepsin $\mathrm{G}$ in the adverse remodelling of stenotic aortic valves. Eur Heart J. 2006; 27(12): 1495-1504, doi: 10.1093/ eurheartj/ehi706, indexed in Pubmed: 16401677.

9. Owen CA, Campbell EJ. Angiotensin II generation at the cell surface of activated neutrophils: novel cathepsin G-mediated catalytic activity that is resistant to inhibition. J Immunol. 1998; 160(3): 1436-1443, indexed in Pubmed: 9570564.

10. Lindstedt KA, Mäyränpää MI, Kovanen PT. Mast cells in vulnerable atherosclerotic plaques--a view to a kill. J Cell Mol Med. 2007; 11(4): 739-758, doi: 10.1111/j.1582-4934.2007.00052.x, indexed in Pubmed: 17760836.

11. Boudier C, Godeau G, Hornebeck W, et al. The elastolytic activity of cathepsin G: an ex vivo study with dermal elastin. Am J Respir Cell Mol Biol. 1991; 4(6): 497-503, doi: 10.1165/ ajrcmb/4.6.497, indexed in Pubmed: 1711351.

12. Chatham WW, Blackburn WD, Heck LW. Additive enhancement of neutrophil collagenase activity by $\mathrm{HOCl}$ and cathepsin G. Biochem Biophys Res Commun. 1992; 184(2): 560-567, indexed in Pubmed: 1315525.

13. Wang J, Sjöberg S, Tang TT, et al. Cathepsin G activity lowers plasma LDL and reduces atherosclerosis. Biochim Biophys Acta. 2014; 1842(11): 2174-2183, doi: 10.1016/j.bbadis.2014.07.026, indexed in Pubmed: 25092171.

14. Kokkonen JO, Vartiainen M, Kovanen PT. Low density lipoprotein degradation by secretory granules of rat mast cells. Sequential degradation of apolipoprotein B by granule chymase and carboxypeptidase A. J Biol Chem. 1986; 261(34): 16067-16072, indexed in Pubmed: 3536921.

15. Schwartz LB, Riedel C, Schratz JJ, et al. Localization of carboxypeptidase A to the macromolecular heparin proteoglycan-protein complex in secretory granules of rat serosal mast cells. J Immunol. 1982; 128(3): 1128-1133, indexed in Pubmed: 6799569

16. Irani AM, Goldstein SM, Wintroub BU, et al. Human mast cell carboxypeptidase. Selective localization to MCTC cells. J Immunol. 1991; 147(1): 247-253, indexed in Pubmed: 2051021.

17. Dougherty RH, Sidhu SS, Raman K, et al. Accumulation of intraepithelial mast cells with a unique protease phenotype in $\mathrm{T}(\mathrm{H}) 2$-high asthma. J Allergy Clin Immunol. 2010; 125(5): 1046-1053.e8, doi: 10.1016/j.jaci.2010.03.003, indexed in Pubmed: 20451039.

18. Lundequist A, Tchougounova E, Abrink M, et al. Cooperation between mast cell carboxypeptidase A and the chymase mouse mast cell protease 4 in the formation and degradation of angiotensin II. J Biol Chem. 2004; 279(31): 32339-32344, doi: 10.1074/ jbc.M405576200, indexed in Pubmed: 15173164.

19. Gilfillan AM, Beaven MA. Regulation of mast cell responses in health and disease. Crit Rev Immunol. 2011; 31(6): 475-529, indexed in Pubmed: 22321108.

20. Xiang M, Sun J, Lin Y, et al. Usefulness of serum tryptase level as an independent biomarker for coronary plaque instability in a Chinese population. Atherosclerosis. 2011; 215(2): 494-499, doi: 10.1016/j.atherosclerosis.2011.01.006, indexed in Pubmed: 21324464.

21. Sata M, Fukuda D. Crucial role of renin-angiotensin system in the pathogenesis of atherosclerosis. J Med Invest. 2010; 57(1-2): 12-25, indexed in Pubmed: 20299739.

22. da Silva AR, Fraga-Silva RA, Stergiopulos N, et al. Update on the role of angiotensin in the pathophysiology of coronary atherothrombosis. Eur J Clin Invest. 2015; 45(3): 274-287, doi: 10.1111/eci.12401, indexed in Pubmed: 25586671.

23. Parikh V, Singh M. Possible role of adrenergic component and cardiac mast cell degranulation in preconditioning-induced cardioprotection. Pharmacol Res. 1999; 40(2): 129-137, doi: 10.1006/ phrs.1999.0501, indexed in Pubmed: 10433871.

24. Najder A. Sense of coherence, smoking status, biochemical cardiovascular risk factors and body mass in blue collar workersshort report. Am J Mens Health. 2018 [Epub ahead of print]: 1557988317748393, doi: 10.1177/1557988317748393, indexed in Pubmed: 29313407.

25. Caughey GH. Mast cell proteases as protective and inflammatory mediators. Adv Exp Med Biol. 2011; 716: 212-234, doi 10.1007/978-1-4419-9533-9_12, indexed in Pubmed: 21713659.

26. Virdis A, Giannarelli C, Neves MF, et al. Cigarette smoking and hypertension. Curr Pharm Des. 2010; 16(23): 2518-2525, indexed in Pubmed: 20550499. 